\title{
A novel web based application for storing, managing and sharing geotechnical data, illustrated using the National soft soil field testing facility in Ballina, Australia
}

J. P. Doherty, S. Gourvenec, F. M. Gaone, J. A. Pineda, R. Kelly, C. O’Loughlin, M. J. Cassidy, S. W. Sloan.

\begin{abstract}
This note describes a web based application for storing, managing and sharing geotechnical research data. The new 'datamap’ web application is a platform for sharing of geotechnical information, freely available to researchers, to create projects and share data either within a specified group or across the public domain. Datamap is illustrated with an example project at the Australian National Field Testing Facility (NFTF), which forms part of the activities of the Australian Research Council Centre for Excellence in Geotechnical Science and Engineering. The example Datamap project illustrates the interactive and accessible nature of the web based application to host in situ and laboratory site investigation data, field testing construction details and monitoring results, reports and bibliography of related papers.
\end{abstract}




\section{Introduction}

Available approaches to management and sharing of geotechnical data are out of step with the pace of change of advances in geotechnical testing techniques, methods of interpretation and development of new design methodologies. Presenting geotechnical data in a well-organized, systematic and easy to access manner is a challenge given the quantity and variety of laboratory, in-situ and field testing performance data and spatial distribution of data across a site. Indeed this is a major challenge in many scientific disciplines, where data is expensive and time consuming to collect and must be accessible to ensure value. The discoverable results of a researcher's work on a particular dataset are typically limited to a published paper. The actual data is likely to remain on the researcher or research institutes' hard drive, disconnected from fellow researchers in the same field. The more researchers that are able to access the same dataset, the more likely it is that this dataset will be transformed into new and useful knowledge. This is consistent with international trends in major science initiatives, such as in the publically accessible use of genetic sequence databases (e.g. see www.ncbi.nlm.nih.gov or www.ensembl.org).

A novel web application, known as "Datamap", has been developed specifically to address the major challenge of capturing, classifying, organizing and making available geotechnical research data. The application uses Google Maps to display pins distributed across a site that represent test locations that have been defined by recording GPS coordinates. Each pin provides a link to data collected from that location. For convenience of use, data can be filtered by location (or Pin ID) and by data (or test) type. This provides an intuitive approach for indexing information using an interactive map that is accessible, i.e. avoiding information overload that occurs with a typical computer file system.

Datamap was developed to allow researchers to create and share "Projects", and therefore provides a general platform for sharing geotechnical research data. Datamap is illustrated in this note with a project at the Australian National Field Testing Facility (NFTF) that forms part of the activities of the Australian Research Council (ARC) Centre of Excellence for Geotechnical Science and Engineering. The purpose of this note is twofold, firstly to showcase the Datamap web application to academics 
and practitioners from around the world and provide guidance on how to access and use the platform, and secondly to share an extensive data set from site investigation and field testing at the Australian National Field Testing Facility (NFTF).

\section{The Australian National Field Testing Facility (NFTF)}

Supported by the Australian Research Council (ARC), the Centre of Excellence for Geotechnical Science and Engineering (CGSE) established the Australian National Field Testing Facility (NFTF) in Ballina, Northern New South Wales (Kelly et al., 2014). The key motivation in establishing the test site was to improve engineering design in soft soils by measuring the engineering properties of the material using a range of in-situ and laboratory tests and then, using this data as input, test the ability of engineering models to predict or back analyze large scale field tests, including embankment and foundation performance.

The Australian NFTF is a 6.5 Ha site on the Richmond River floodplain, located south of Emigrant Creek and west of Fishery Creek in Ballina, NSW, Australia. An aerial photograph of the site is shown in Figure 1 and layout of the site investigation and site works is shown inFigure 1 Figure 2. Ground conditions comprise a crust of alluvial clayey silty sand to a depth of about $1.5 \mathrm{~m}$, underlain by soft estuarine clay, underlain by a transition zone of clay, silt and sand, then sand of varying thickness (Kelly at al. 2014). The thickness of the soft estuarine clay increases from approximately 12 to $22 \mathrm{~m}$ from west to east. The engineering geology at the site is described in detail by Bishop (2004), Bishop \& Fityus (2006) and Kelly et al. (2016).

At the Australian NFTF, three large scale trial embankments have been built (Kelly et al., 2014), four large scale footing load tests conducted, numerous bore holes drilled with high quality soil samples collected and tested in a range of laboratory apparatus (Pineda et al., 2014; Pineda et al., 2016a,b) and a range of in-situ tests including cone (Kelly et al, 2016, Li et al, 2014 and Li et al, 2016), ball and Tbar (Colreavy et al., 2016) penetrometer tests and self-boring pressuremeter tests (Gaone at al 2016). 
Published in Computers in Geotechnics (special issue) http://dx.doi.org/10.1016/j.compgeo.2017.05.007

One of the aims in establishing the Australian NFTF was to leave a lasting legacy to the engineering community by making the data freely available in digital form. This will ensure that this comprehensive data set can be reused by academics and practitioners from around the world and therefore maximize the impact of this publically funded research project.

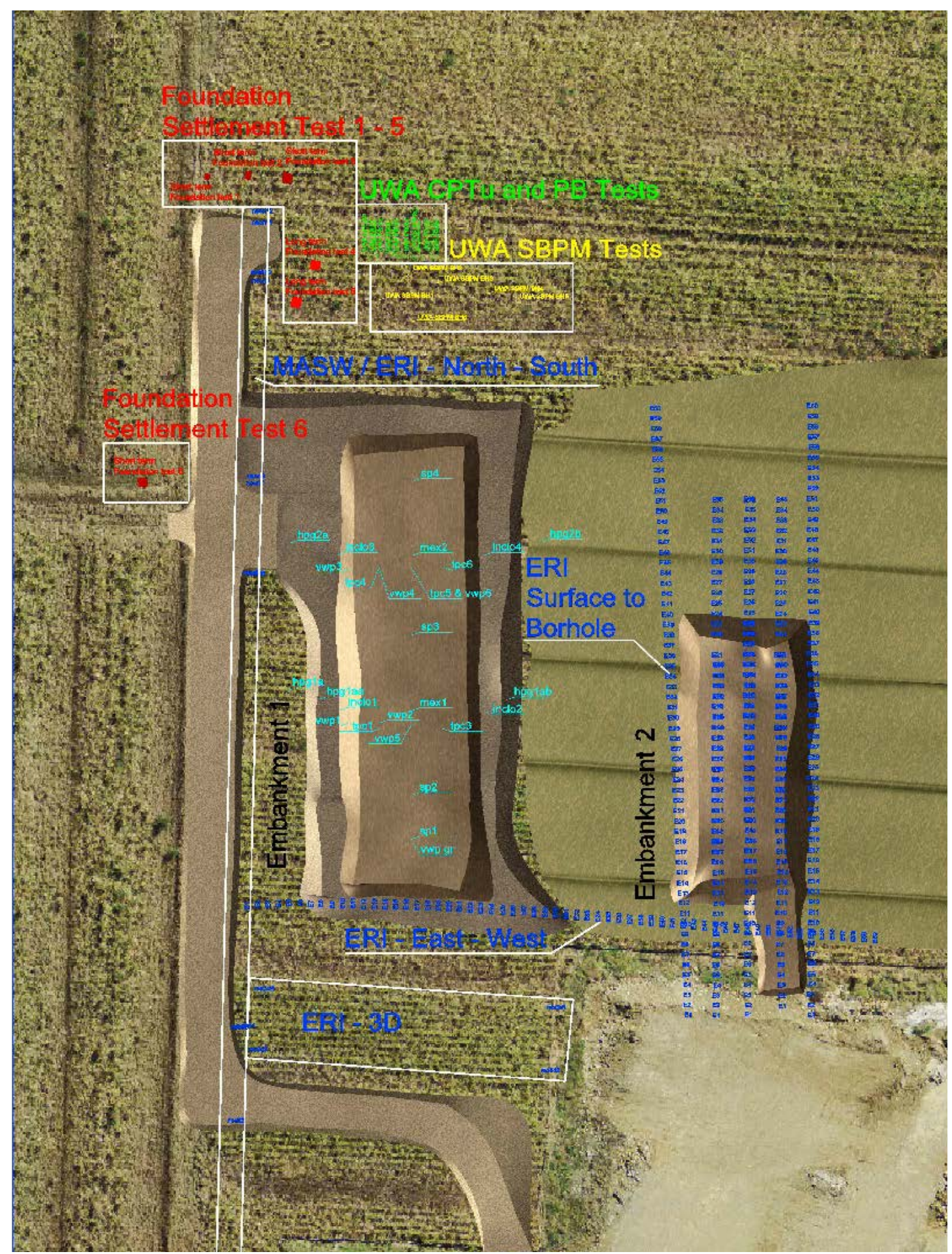

Figure 1: Aerial photograph and site layout of the Australian National Field Testing Facility (NFTF) 


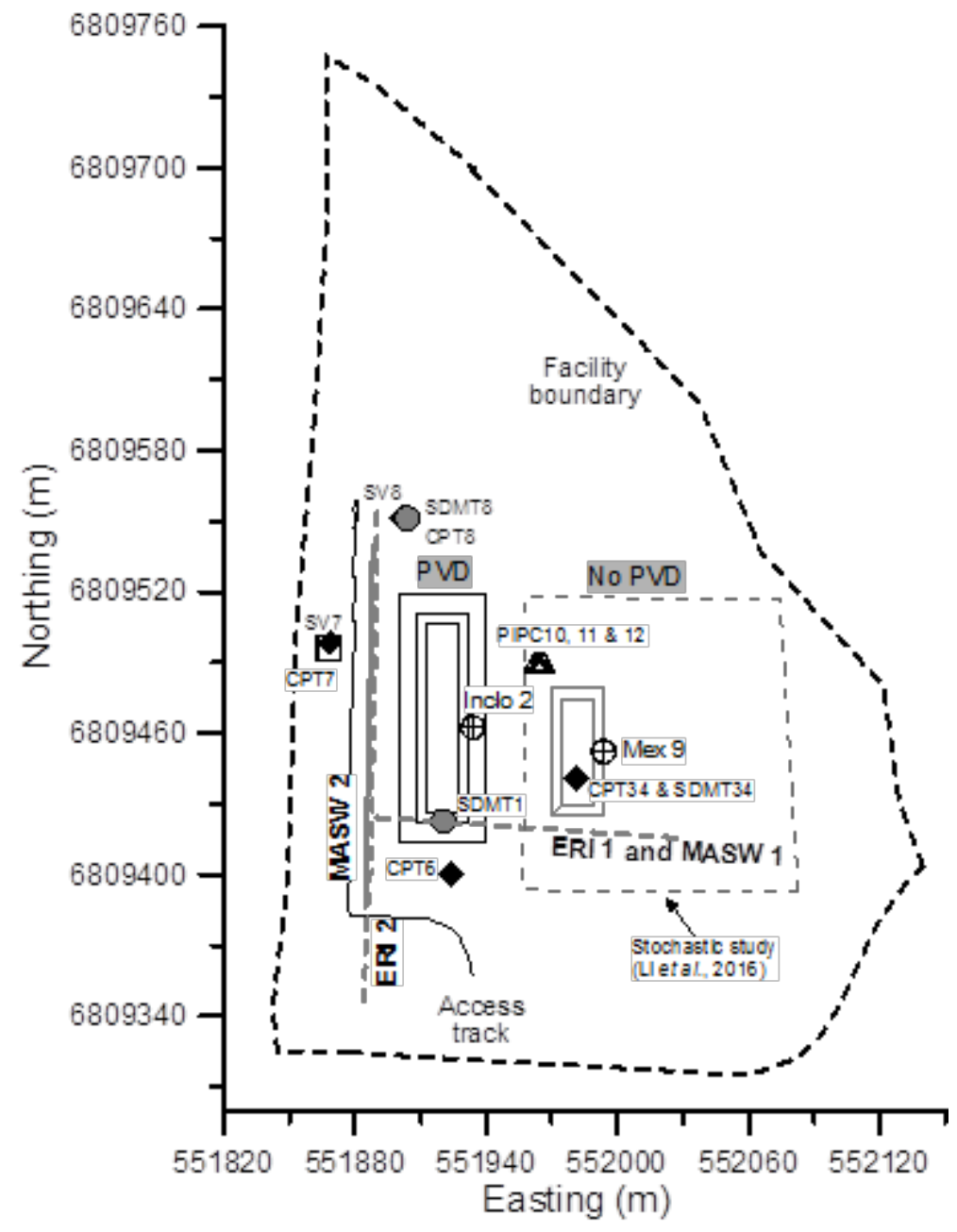

Figure 2: Site plan of the Australian National Field Testing Facility (NFTF) 


\section{Datamap}

\section{Accessing the NFTF dataset}

Access to the NFTF dataset can be accomplished in two simple steps. First users register with the system at www.geocalcs.com/datamap by completing the web form shown in Figure 3.

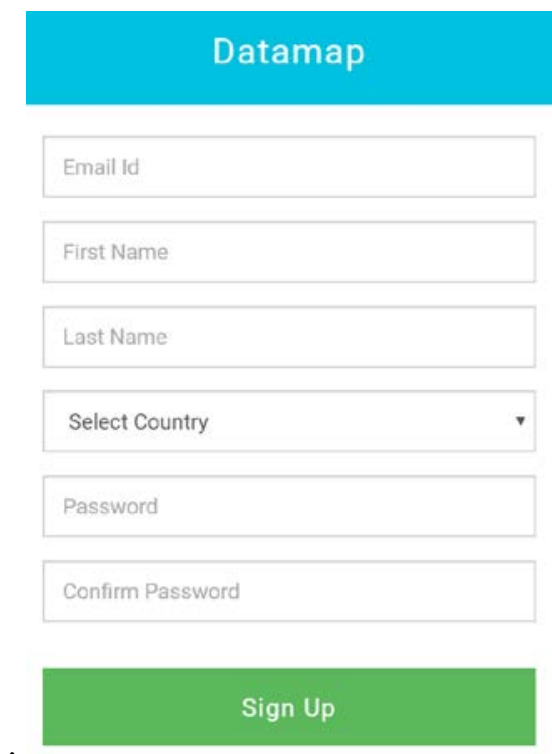

Figure 3: Datamap registration screen shot

Once logged in, navigate to the "Join Project" tab (shown in Figure 4) by first clicking the "My Projects” link in the upper right hand corner of the map viewing screen. Then, enter the details in Table 1 and click on the "Join Project" button. Then navigate back to the Map view by clicking on a link in the upper right corner.

Table 1: Project details to access NFTF project data

\begin{tabular}{ll}
\hline Project name: & NFTF \\
\hline Project code: & Ballina \\
\hline
\end{tabular}




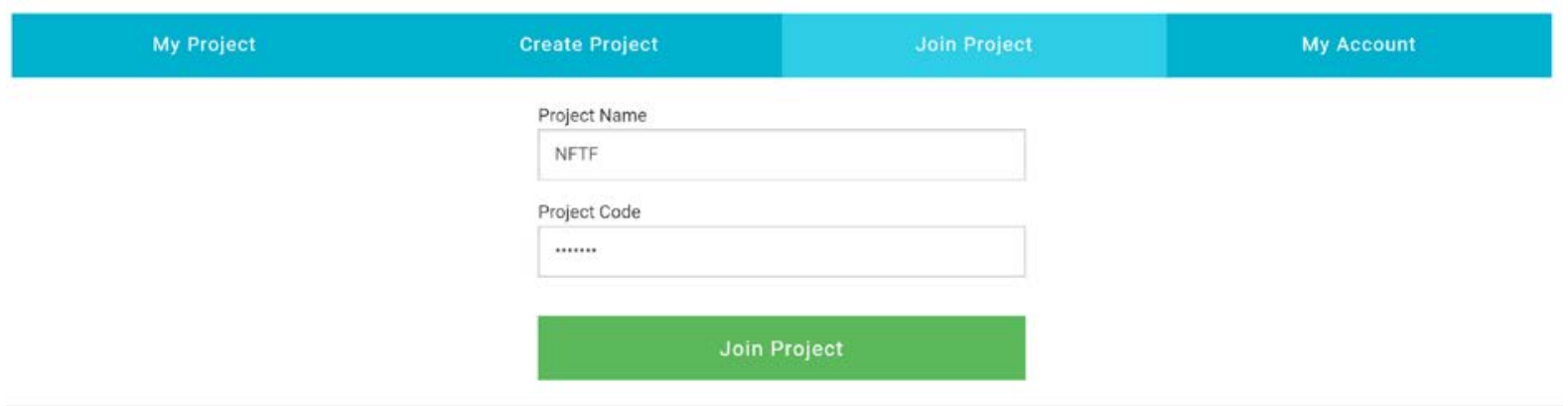

Figure 4: Datamap “Join project” screen shot

\section{Interacting with the data}

In view mode, Google Maps is used to display pins that represent test locations over the site (see Figure 5). Each pin provides a link to data collected from that location.
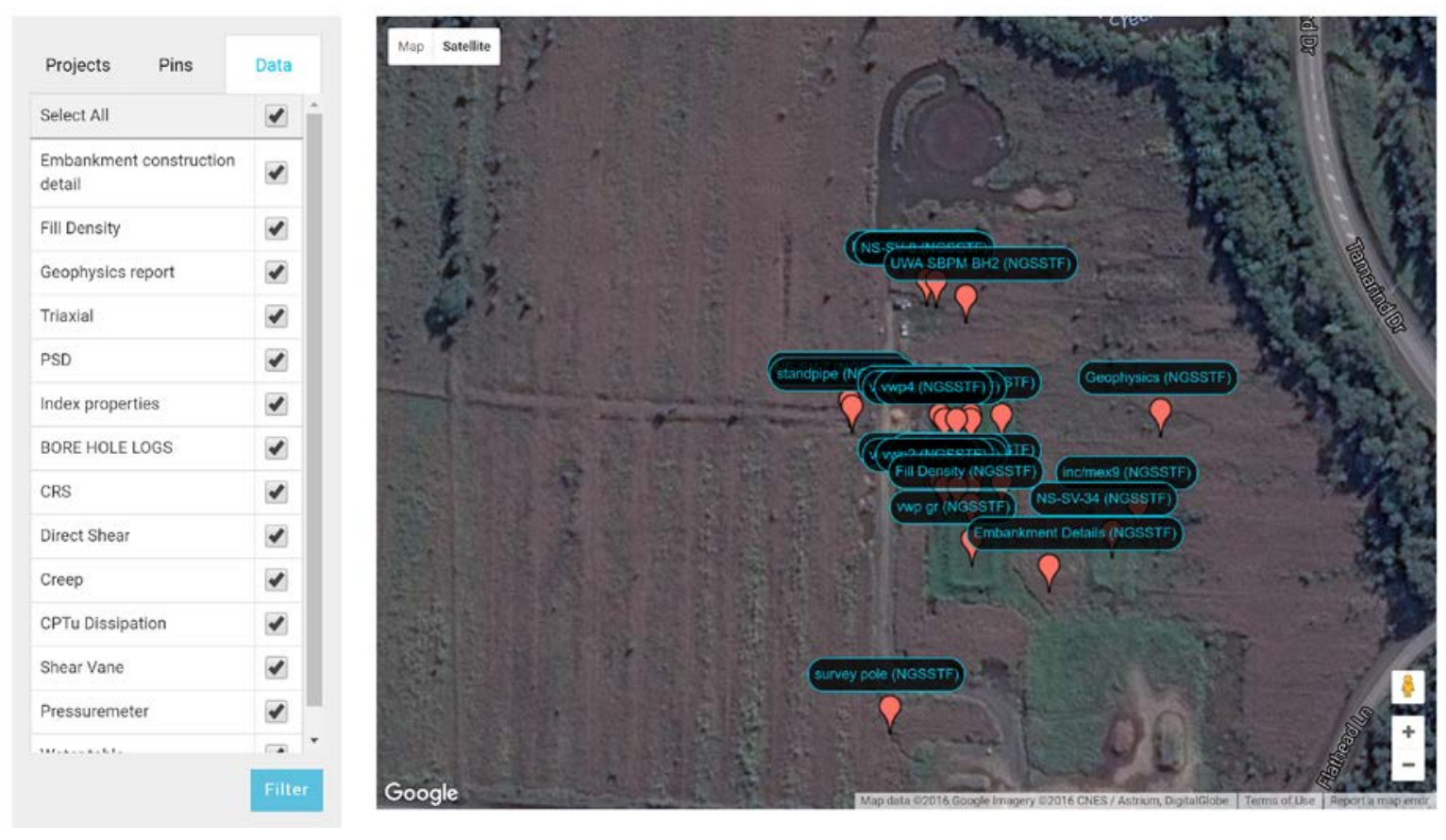

Figure 5: Datamap overview with current data pins at the NFTF

When a pin is selected, the metadata, or information about the data, associated with that pin is displayed (see Figure 6). This includes the "Data ID" and the "Data type" and an image that provides a preview of the data that is stored. Users can then download the file containing the data by clicking on the "Download file" button. Files can be of any type, but are usually in the form of Microsoft 
Excel for measure data and pdf for reports. The preview images are png or jpeg files and these can also be selected and saved locally. Figure 6 shows a screen shot of the menu that appears when Pin MEX9 is select. This Pin currently has 11 triaxial tests associated with it. Each test can be individually accessed using the scroll bar on the right hand side of the pop up screen. There is effectively no limit to the amount of data each pin can hold.
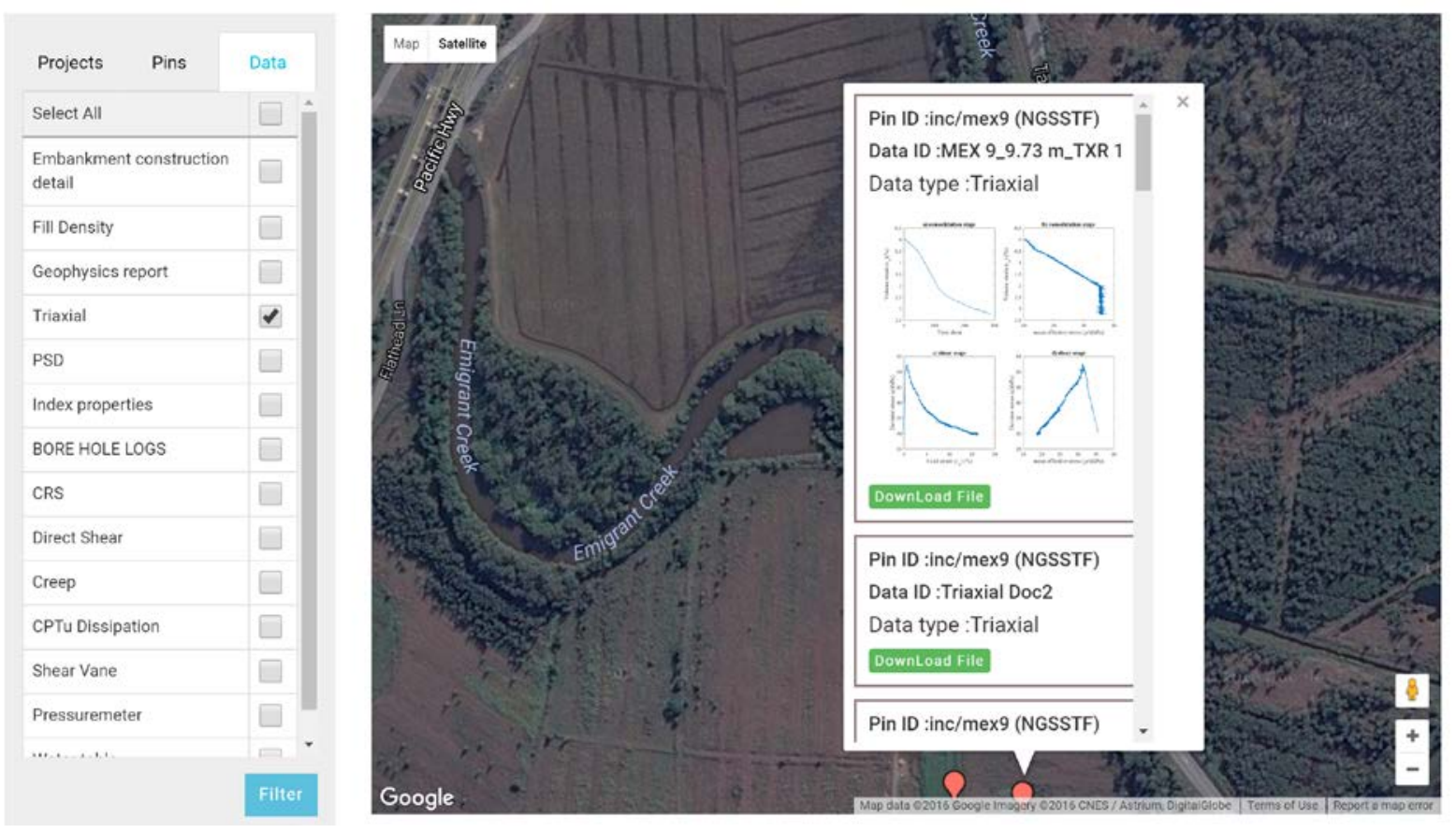

Figure 6: Pin selection with image previewing the data in Datamap

The left hand side of the screen provides users with the ability to filter the data by Pin ID or "Data type”, so that information of interest can be easily identified. For example, if a user is interested in only "Triaxial" data, then the check box next to the "Triaxial" can be selected and after hitting the filter button, the only two pins that contain triaxial data remain (see Figure 7). 

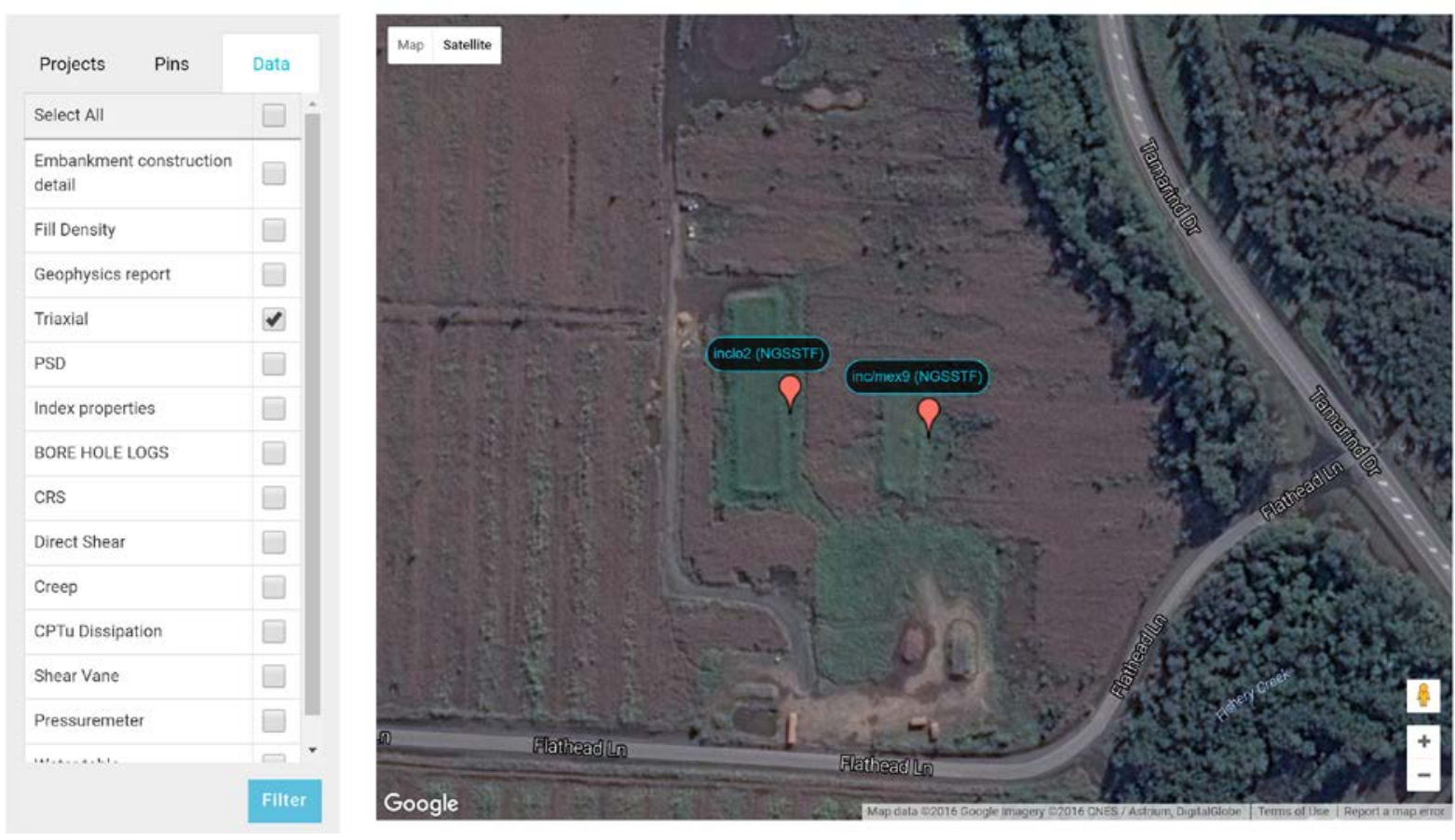

Figure 7: Illustration of filtering by data type in Datamap

\section{Creating a project}

Datamap was developed as a general platform to enable researchers to create their own projects and share data. A user can create a project by selecting "My Projects" from the Map view screen and selecting “Create Project”, as shown in Figure 8.

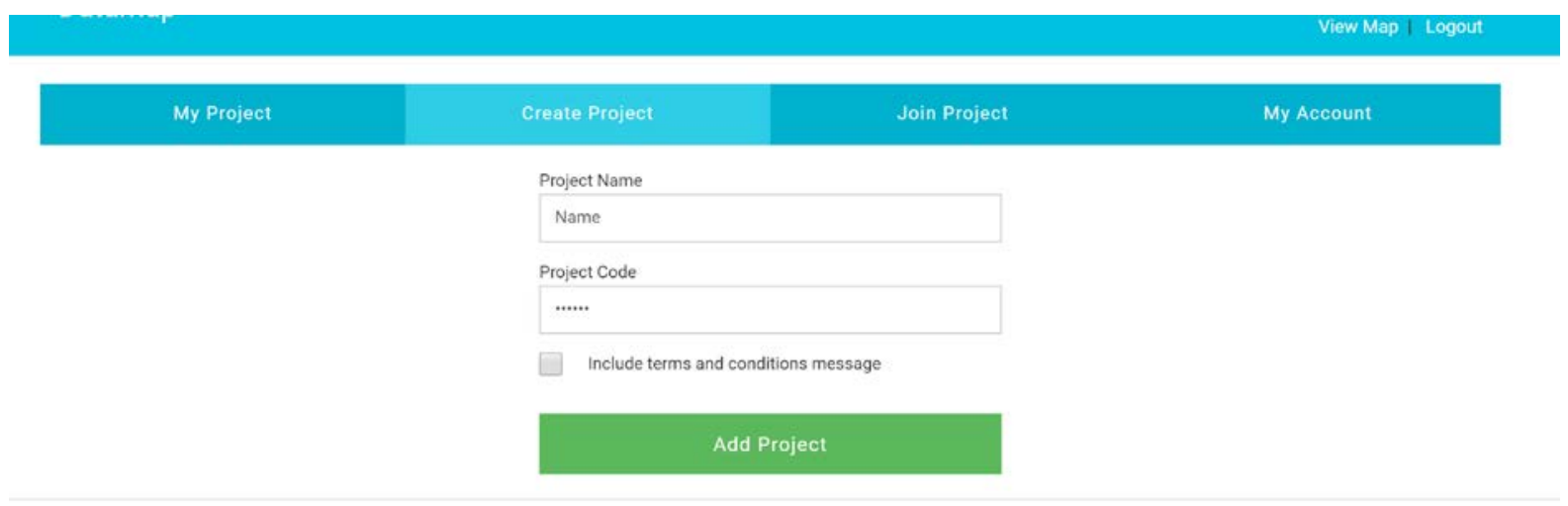

Figure 8: Creating a new project in Datamap

A project name must be entered, along with a project code. These details are required by other users to access the data contained within the project. Access details can be shared with a few colleagues and treated much like a secure user name and password, or, as in the case with the NFTF project, they can 
be published to allow anyone to access the data. A "terms and conditions" message can also be specified, so that when a user joins the project, they must agree to specific terms and conditions in accessing the data.

Once a project is created it can then be selected for editing from the list of projects. There are four main menu options in editing a project, as shown in Figure 9.

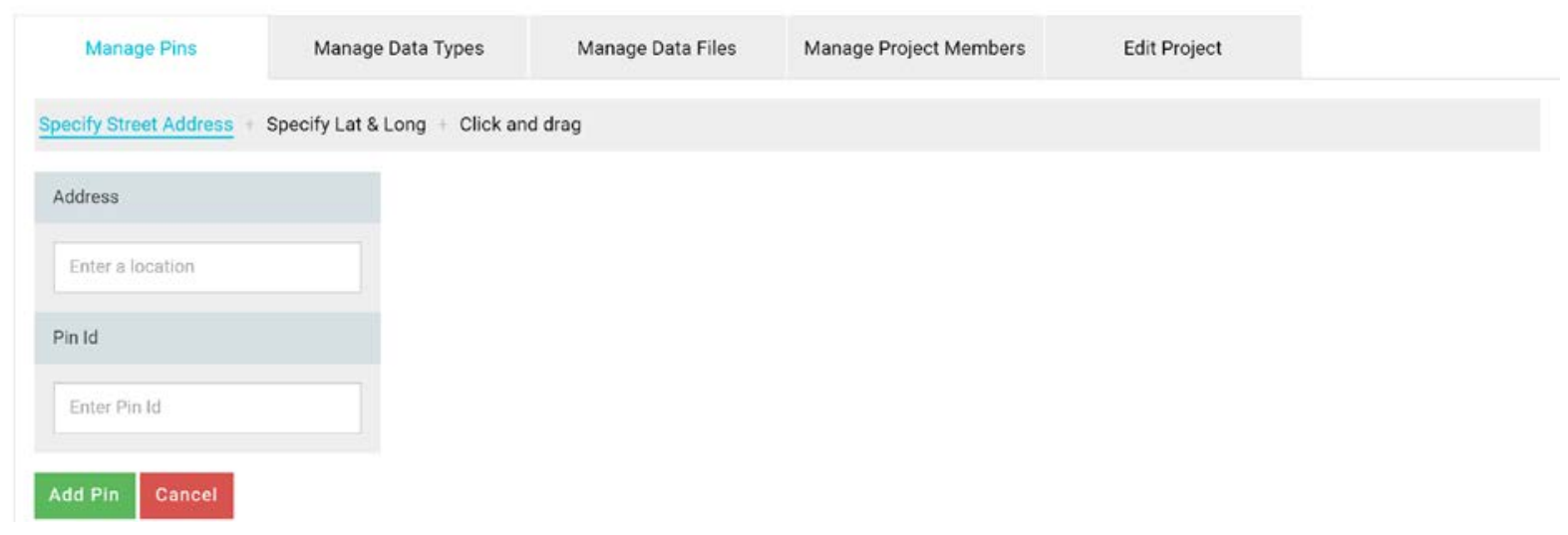

Figure 9: Managing a project in Datamap

Pins can be added to the map under the "Manage Pins". This can be done using a street address, by specifying latitude and longitude or by clicking and dragging an iterative pin on a map. Managing data types simply involves specifying the types of data the project will be contained within the project so they can be sorted or filtered later. For example, Figure 7 shows the data types that were created for the NFTF project. Managing data files involves uploading data files and associating them with an existing pin and data type and adding a png or jpg file that is used to provide a preview to the data (for example the images that can be seen in Figure 6). Under 'manage project members', users who have joined the project can be seen and selected users can be given extra user privileges that allow them to add or remove data.

\section{System architecture}

Datamap was built specifically for the Amazon Web Services (AWS) cloud platform. The system architecture, which is illustrated in Figure 10, consists of an elastic load balancer distributing traffic 
between AWS EC2 instances that act as web servers in separate AWS availability zones. An EC2 instance is a virtual server in Amazon's Elastic Compute Cloud (EC2) for running applications on the Amazon Web Services (AWS) infrastructure. All data files are stored in Amazon S3, which is a secure, durable and highly-scalable object storage service. The locations of files on S3 are stored as compact strings on a light weight MySQL database, which also stores user details and other project related Metadata. The web servers are stateless, meaning they do not store any session or project information. This means that if web traffic exceeds the capacity of the two web servers, then additional webservers can be simply added and traffic distributed to the additional servers via the elastic load balancer. The existing web servers also reside in separated AWS availability zones. Each AWS availability zone is physically distinct from another, with separate power supply and data cables. This means that a fault in one availability zone will not impact another. The elastic load balancer is able to detect if there is an outage in a particular availability zone and if so will divert all traffic to the other. This system architecture ensures, that the web application is highly available.

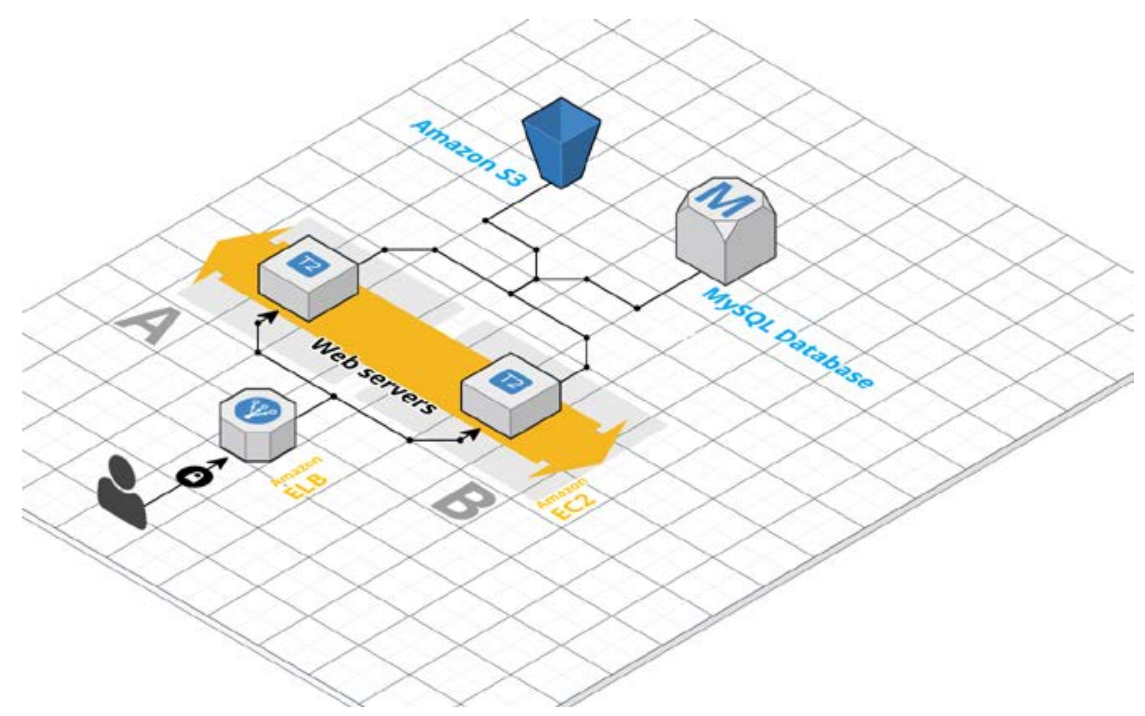

Figure 10: System architecture (created using Cloud Craft) 


\section{Conclusions}

This note has described a new platform for capturing, classifying, organizing and making available geotechnical research data. The platform is illustrated using data from the Australian National Field Testing Facility (NFTF) which is part of the ARC Centre of Excellence for Geotechnical Science and Engineering (CGSE). The application was built using modern cloud-based technologies that minimize the hosting cost, maximize the reliability and allow scaling to handle an unlimited quantity of data and simultaneous user access. The application ensures that this comprehensives data set can be reused by academics and practitioners from around the world and will therefore help maximize the impact of this publically-funded research project. Datamap also enables users to setup and manage other projects, providing a general platform for sharing geotechnical information.

\section{Acknowledgements}

This work forms part of the activities of the Centre for Offshore Foundation Systems (COFS). Established in 1997 under the Australian Research Council’s Special Research Centres Program. Supported as a node of the Australian Research Council's Centre of Excellence for Geotechnical Science and Engineering (CGSE) CE110001009, and through the Fugro Chair in Geotechnics, the Lloyd's Register Foundation Chair and Centre of Excellence in Offshore Foundations and the Shell EMI Chair in Offshore Engineering. This support is gratefully acknowledged. 


\section{References}

Bishop, D.T. (2004) A proposed geological model and geotechnical properties of a NSW estuarine valley: a case study. Proc. 9th ANZ conference, Auckland, 261-267.

Bishop, D.T. and Fityus, S. (2006) The sensitivity framework: Behaviour of Richmond River estuarine clays, Australian Geomechanics Society, Sydney Chapter mini-symposium, 167-178.

Colreavy C, O'Loughin C. \& Randolph M. (2016) Estimating consolidation parameters from field piezoball tests. Géotechnique 66, No. 4, 333-343

Gaone, F. M., Doherty, J.P Gourvenec, S., \&. (2016). Self-boring pressuremeter tests at the National Field Testing Facility, Ballina NSW. In 5th International Conference on Geotechnical and Geophysical Site Characterisation

Kelly, R. B. (2013). Australia’s first national facility for soft soils testing. Civil Engineers Aust. June, 76-78.

Kelly, R.B., C.D. O’Loughlin, L. Bates, S.M. Gourvenec, C. Colreavy, D.J. White, F.M. Gaone, J.P. Doherty, M.F. Randolph (2014). In situ testing at the national soft soil field testing facility, Ballina, New South Wales. Australian Geomechanics Vol 49 No 4, 13-26.

Kelly, R.B., Pineda J.A., Bates L., Suwal L. \& Fitzallen I. (2016) Site Characterisation for the Ballina Field Testing Facility. Géotechnique (in print)

Li, J.H., Cassidy, M.J., Kelly, R., Zhang, L., Huang, J. (2016). Probabilistic identification of soil stratification. Géotechnique, Vol. 66, No. 1, pp. 16-26. DOI: http://dx.doi.org/10.1680/jgeot.14.P.242

Li, J.H., Huang, J.S., Cassidy, M.J., Kelly, R. (2014). Spatial variability of the soil at the Ballina National Field Test Facility. Australian Geomechanics, Vol. 49, No. 4, 41-48. 
Nash, D. F. T., Powell, J. J. M. \& Lloyd, I. M. (1992). Initial investigation of soft clay test site at Bothkennar. Geotechnique 42, No. 2, 163-181

Pineda, J., Suwal, L. P., Kelly, R. (2014). Sampling and laboratory testing of Ballina clay. Australian Geomechanics Vol 49 No 4, 13-26

Pineda, J.A., Suwal, L., Kelly, R.B., Bates, L. \& Sloan, S.W. (2016a) Characterization of Ballina clay. Géotechnique, 66(7), 556-577.

Pineda, J.A., Liu, X-F. \& Sloan, S.W. (2016b) Tube sampling in soft clays: a microstructural insight. Géotechnique, doi: 10.1680/jgeot.15.P.217 